\title{
SARS-CoV-2 Direct Real Time PCR without RNA Extraction: Appropriate Method or Not?
}

Spandan Chaudhary, Disha Patel, Kavisha Vyas, Pooja Chaudhary, Prathana Singhania, Juhi Patel, Ekta Jajodia, Nilay Dave, Shiv Patel, Ramachandiran Sivaramakrishnan, Mayank Patadiya, Tushar Sonagara, Ashish Hirpara, Neeraj Arora

\section{ABSTRACT}

Real time PCR (RT-PCR) detection method is the widely used for COVID19 virus detection. This includes sample collection in viral transport medium (VTM), viral RNA extraction followed by detection of virus using fluorescence dye-based system using RT-PCR machine. Several studies have demonstrated a new method which replaces the extraction step by a simple method involving DTT and Proteinase-K and heat treatment. ICMR and few other governing bodies have approved such protocols but are they appropriate in clinical context? In present study, we tried to evaluate one such protocol by using ICMR and WHO approved COVID-19 detection protocol (of CoviPath ${ }^{\text {TM }}$ COVID-19 RT-PCR Kit) by replacing RNA extraction step. We used 228 clinical COVID-19 samples for studying method which includes 176 positive (CT values from 14 to 23 ; 24 to 31 and 32 to 37 were considered as high, moderate and low positive respectively) and 52 negative nasopharyngeal and oropharyngeal swabs samples. We got $100 \%$ concordant results with negative samples and $92 \%$ concordant and $8 \%$ non-concordant results for positive samples. Non-concordant results are with low positive samples. Low level of positivity in the samples could indicate the initial/end stage of COVID-19 disease. If they are at the initial stage, they can be the potential carrier and spread the disease. Authors believe that direct methods can be used for screening bit not for diagnosis of COVID-19 disease.

Keywords: COVID-19, Direct RT-PCR, DTT, Proteinase-K.

Submitted: November 30, 2021

Published: January 27, 2022

ISSN:2593-8339

DOI:10.24018/ejmed.2022.4.1.1164

S. Chaudhary*

Unipath Specialty Laboratory Ltd, Ahmedabad, India.

(e-mail:

spandan.chaudhary@gmail.com)

D. Patel

Unipath Specialty Laboratory Ltd, Ahmedabad, India.

K. Vyas

Unipath Specialty Laboratory Ltd, Ahmedabad, India.

P. Chaudhary

Unipath Specialty Laboratory Ltd,

Ahmedabad.

P. Singhania

Unipath Specialty Laboratory Ltd, Ahmedabad.

J. Patel

Unipath Specialty Laboratory Ltd, Ahmedabad

E. Jajodia

Unipath Specialty Laboratory Ltd, Ahmedabad.

N. Dave

Unipath Specialty Laboratory Ltd, Ahmedabad.

S. Patel

Unipath Specialty Laboratory Ltd,

Ahmedabad.

R.Sivaramakrishnan

Unipath Specialty Laboratory Ltd,

Ahmedabad.

M. Patadiya

Unipath Specialty Laboratory Ltd, Ahmedabad.

T. Sonagara

Unipath Specialty Laboratory Ltd, Ahmedabad.

A. Hirpara

Unipath Specialty Laboratory Ltd, Ahmedabad.

N. Arora

Unipath Specialty Laboratory Ltd, Ahmedabad.

${ }^{\star}$ Corresponding Author 


\section{INTRODUCTION}

The SARS-CoV-2 (Severe Acute Respiratory Syndrome Coronavirus 2) is the causative agent of the global pandemic Coronavirus Disease (COVID-19). To prevent the spread of the infection in the community, high-volume testing together with case isolation and contact tracing is one of the most effective strategies adapted by most countries worldwide [1].

SARS-CoV-2 is an enveloped RNA virus of the betacoronavirus genus the family Coronaviridae, and the order Nidovirales [2]. Four subfamilies of coronaviruses are known: alpha, beta, gamma, and delta. Alpha and beta coronaviruses originate from mammals, especially bats whereas gamma and delta originate from birds and pigs [3]. As per the whole-genome sequencing analysis studies, SARS-CoV-2 is genetically related to SARS-CoV of the 2003 outbreak [4]. SARS-CoV-2 was found to infect more human beings than either of its predecessors that include the SARS-CoV and the Middle East respiratory syndrome virus (MERS) [5]. The SARS-CoV-2 carries non-segmented positive strand RNA genome of $30 \mathrm{~kb}$ belonging to subgenus Sarbecoviruses. The viral contains four structural proteins and sixteen nonstructural proteins [6]. The four major structural genes encode the nucleocapsid protein $(\mathrm{N})$, spike protein (S), membrane glycoprotein (M), and small membrane protein (SM) [3].

SARS-CoV-2 is the most infectious amongst all the reported pathogens till now. The virus enters the host cells through the angiotensin converting enzyme-2 (ACE2) receptor using the receptor-binding domain of the $\mathrm{S}$ protein [7]. Upon infection, beta-coronaviruses use a virus-encoded RNA-dependent RNA-polymerase to generate a minusstrand RNA copy of their genome in the host cell [8]. Infected host cells contain plus and minus strand RNAs of the coronavirus with excess of transcripts derived from the 3 ' end of its genome as virus synthesizes sub genomic minus strand RNAs, which are complementary to the 3' end of the viral genome [8]-[10]. After 2 to 14 days of viral exposure, symptoms will start appearing which includes fever, cough, shortness of breath, chills, muscle, pain, pressure in the chest, headache, sore throat, confusion, bluish lips on the face, anosmia and impaired taste [7]. Though a very few of the infected individuals develop serious symptoms, such as severe pneumonia, acute respiratory distress syndrome (ARDS), and sepsis, leading to the death of the infected patient, this virus is considered highly pathogenic.
Similar to other pathogenic RNA viruses, confirmation of COVID-19 infection depends upon the molecular biological detection of the viral genome and its transcripts in patient samples by nucleic acid amplification techniques (NAATs) [11]. To allow sensitive and accurate detection of viral ribonucleic acids, primary patient samples such as nasopharyngeal and oropharyngeal swabs are further processed to isolate the total RNA. The RNA is then reverse transcribed into cDNA by using one step reverse transcriptase enzyme followed by PCR amplification of targeted viral genes by a thermo-stable DNA-dependent DNA polymerase using specific primers-probes to detect and analyze the presence of SARS-CoV-2 sequences. As per WHO recommendations, RT-PCR amplifications in two regions of the viral genome is required for testing the clinical samples to confirm SARS-CoV-2. The structural E region and the nonstructural RdRp region are the mostly used regions for detection of virus followed by genes encode the nucleocapsid protein $(\mathrm{N})$ and spike protein $(\mathrm{S})$. Viral emergence and global spread of infection led to high demand for testing kits and reagents. This caused delay in development and supply of testing kits, reagents and ultimately the screening of infected individuals. The extraction free processing of COVID-19 detection attracted the laboratory authorities due to reduced turnaround time, less manual handling errors and cost efficacy.

Several studies have reported use of direct PCR methods without extraction to detect SARS-CoV-2 in clinical samples. One study [12] used pre-heating of sample at 70 degrees before RT-PCR Amplification which resulted an average increase in the $\mathrm{Ct}$ values of 6 , leading to a false negative rate of $12 \%$. Another study [13] used direct RT-PCR for sputum and nasopharyngeal exudates spiked with a plasmid containing the SARS-CoV-2 N gene. They found lowest limit of detection (LOD) of 2 copies per reaction for spiked sputum and 20 copies per reaction for spiked nasal exudates. One of the studies reported to obtain best sensitivity by using $140 \mu \mathrm{l}$ sample volume with heat treatment of respiratory samples followed by RT-PCR [14]. Their results were evident enough to replace existing extraction protocol. Reference [15] found that heat inactivation of the samples at $95^{\circ} \mathrm{C}$ prior to $\mathrm{PCR}$ reactions resulted better results than the incubation at $65^{\circ} \mathrm{C}$. Few studies conducted on the similar protocol omitting the extraction step have found lower sensitivity and are listed in Table I.

TABLE I: LIST OF STUDIES COMPARED STANDARD COVID-19 DETECTION METHOD WITH DIRECT (WITHOUT RNA EXTRACTION STEP) PROTOCOL WITH SOME MODIFICATIONS, HEAT TREATMENT OR BY USING ALTERNATIVE REAGENTS/ CHEMICALS

\begin{tabular}{|c|c|c|c|c|}
\hline S.N. & Reference & $\begin{array}{l}\text { Number of } \\
\text { samples }\end{array}$ & $\begin{array}{c}\text { Concordance } \\
\text { with Standard } \\
\text { methods } \\
\end{array}$ & Comments \\
\hline 1 & {$[16]$} & 59 & $98 \%$ & $\begin{array}{l}\text { Compared direct RT-qPCR with four different RNA extraction kits Qiagen, Invitrogen, BGI } \\
\text { and Norgen Biotek and found that BGI extraction free protocol provided } 78.4 \% \text { sensitivity }\end{array}$ \\
\hline 2 & {$[17]$} & 130 & $100 \%$ & $\begin{array}{c}\text { Tested on } 130 \text { samples, found } 100 \% \text { concordance with the standard protocol with an average } \\
\text { difference in } \mathrm{Ct} \text { values of } 4.38 \text { for the E gene and } 3.85 \text { for the RdRp gene }\end{array}$ \\
\hline 3 & [18] & 185 & $95 \%$ & 185 samples were analyzed with sensitivity of $79 \%$, a specificity of $100 \%$ \\
\hline 4 & {$[14]$} & 135 & $95 \%$ & $\begin{array}{l}135 \text { samples tested with the limit of detection (CT value at which } 95 \% \text { of known positives are } \\
\text { correctly identified) for the without extraction approach to be a clinical CT of } 32\end{array}$ \\
\hline 5 & [19] & 30 & $95 \%$ & $\begin{array}{c}30 \text { patient samples with high viral load (Low CT values }<30 \text { ) were found to be } 100 \% \\
\text { correlation in results but the sensitivity was slightly reduced in samples with high CTs (CT } \\
\text { value }>30)\end{array}$ \\
\hline 6 & [20] & 130 & $94 \%$ & $\begin{array}{c}\text { Authors concluded that direct RT-qPCR protocol can be a safe alternative for SARS-CoV-2 } \\
\text { diagnosis but only in the case of a shortage of reagents for RNA extraction with some clinical } \\
\text { impact. }\end{array}$ \\
\hline
\end{tabular}


Commonly used lab tests for detection of COVID-19 in patient sample includes two major steps: 1) RNA extraction and purification from biological sample (nasopharyngeal swab, sputum, or other); followed by 2) targeted detection of SARS CoV 2 RNA by reverse transcription-quantitative PCR (RT qPCR) assay. By mid-March of 2020 many countries have witnessed the shortage of extraction kits and reagents for manual kits as well as reagents and supplies for the larger automated instruments with uncertain supply chains [21][23]. In present study, we developed a method for direct RNA extraction from samples transported in viral transport medium (VTM) using two chemicals: Proteinase-K (PK) and dithiotheritol (DTT) and high temperature incubation. DTT protects the RNA by deactivating RNases [24] and PK increases yield by digesting proteins in the samples which are bound with RNA. We used 1:1 diluted samples and treated them with aforementioned two chemicals followed by RTPCR reaction set up using TaqPath ${ }^{\text {TM }}$ COVID-19 Combo Kit (cat no. A47814). We used 228 clinical COVID-19 samples for studying new method which includes 176 positive and 52 negative nasopharyngeal and oropharyngeal swabs samples in viral transport medium. We got $100 \%$ concordant results with negative samples and $91.23 \%$ concordant results for positive samples, approx. $8 \%$ of non-concordant results are with low positive samples. Studies have shown that, patients with low viral loads are less infectious, and several studies suggest that while patients with $\mathrm{Ct}$ values $\leq 25$ are likely to be infectious, those with clinical Ct values above 33-34 are not, but strong clinical data is not available [25]-[27]. Results of this study and review of literature of related studies showed lesser sensitivity and specificity while using COVID-19 detection without RNA extraction step; this raises serious concerns about usage of the same in clinical context.

\section{MATERIALS AND Methods}

\section{A. Patient Samples and Ethics Statement}

Nasopharyngeal and oropharyngeal swab samples of patients were collected in VTM as per Indian Council of Medical Research (ICMR) guidelines at state government authorized COVID-19 test centre-Unipath specialty laboratories, Ahmedabad, Gujarat.

\section{B. Samples}

Total 228 clinical COVID-19 samples were used in the current study which includes 176 positive and 52 negative samples. Samples were processed for automated RNA extraction using KingFisher ${ }^{\mathrm{TM}}$ Flex Magnetic Particle Processor with 96 DeepWell Head followed by RT-PCR reaction using TaqPath ${ }^{\mathrm{TM}}$ COVID-19 Combo Kit (cat no. A47814). Generated results were considered as reference results for new protocol under study.

\section{Experimental Design}

All the clinical samples included in the study were subjected to RNA extraction using $200 \mu \mathrm{L}$ sample volume protocol following instruction manual. Isolated RNA was subjected to COVID-19 detection using TaqPath ${ }^{\text {TM }}$ COVID19 Combo Kit (cat no. A47814) on QuantStudio ${ }^{\text {TM }}$ Real-Time PCR Instrument using half reaction volume i.e. $12.5 \mu \mathrm{L}$ than recommended reaction volume $(25 \mu \mathrm{L})$ in the user manual (Publication Number MAN0019181). In RT-PCR assay using mentioned kit, we have already validated the results comparison of $12.5 \mu \mathrm{L}$ reaction volume and $25 \mu \mathrm{L}$ reaction volume and got $100 \%$ concordance terms of CT values (data not provided). Results analyzed based on cycle threshold (CT) values obtained from RT-PCR analysis. CT values between 13 to 37 were considered as positive and rest were considered as negative.

\section{Methodology}

In present study, positive samples were divided into three parts: samples with CT values from 14 to 23 were termed as high positive, samples with CT values from 24 to 31 were termed as moderate positive and samples with $\mathrm{CT}$ values from 32 to 37 were termed as low positive. Same samples have been used for the experiment in current study. Results were co-related clinically with the disease symptoms. In present study, we use the RT-PCR results based clinically confirmed 228 samples for the modified extraction protocol. Briefly, $10 \mu \mathrm{L}$ samples were taken from VTM and diluted 1:1 with nuclease free water in 96 well PCR plate. A master mix was prepared containing $0.1 \mu \mathrm{L}$ of $0.1 \mathrm{M}$ Dithiotheritol (DTT) (Invitrogen, $\mathrm{P} / \mathrm{N}$ y00147) and $2 \mu \mathrm{L}$ of $20 \mathrm{mg} / \mathrm{ml}$ of ProteinaseK (Cat no. 19131) per sample and added to diluted sample. Samples were than subjected to heat incubation at $56^{\circ} \mathrm{C}$ for 15 minutes, $70^{\circ} \mathrm{C}$ for 10 minutes and $95^{\circ} \mathrm{C}$ for 10 minutes in a thermal cycler. After incubation was completed, $5 \mu \mathrm{L}$ of sample was subjected to RT-PCR reaction using TaqPath ${ }^{\mathrm{TM}}$ COVID-19 Combo Kit as per user manual. RT-PCR reaction used was comprising of $3.125 \mu \mathrm{L}$ of TaqPath ${ }^{\mathrm{TM}}$ 1-Step Multiplex Master Mix (No ROX $\left.{ }^{\mathrm{TM}}\right)(4 \mathrm{X}), 0.625 \mu \mathrm{L}$ of COVID-19 Real Time PCR Assay Multiplex, 3.75 $\mu \mathrm{L}$ of nuclease free water and $5 \mu \mathrm{L}$ of RNA. Known positive and known negative control samples were included in the PCR set up to avoid false results. After the reaction set up, PCR plate was inserted into QuantStudio ${ }^{\text {TM }}$ Real-Time PCR Instrument following the COVID-19 PCR program according to the manufacturer's instructions. The kit detects $\mathrm{S}$ gene, $\mathrm{N}$ gene and ORF gene from SARS-Cov-2 and MS2 gene as internal PCR control. Samples were analyzed with CT values for each gene and results were recorded. Illustrative image of methodology part is presented in Fig. 1.

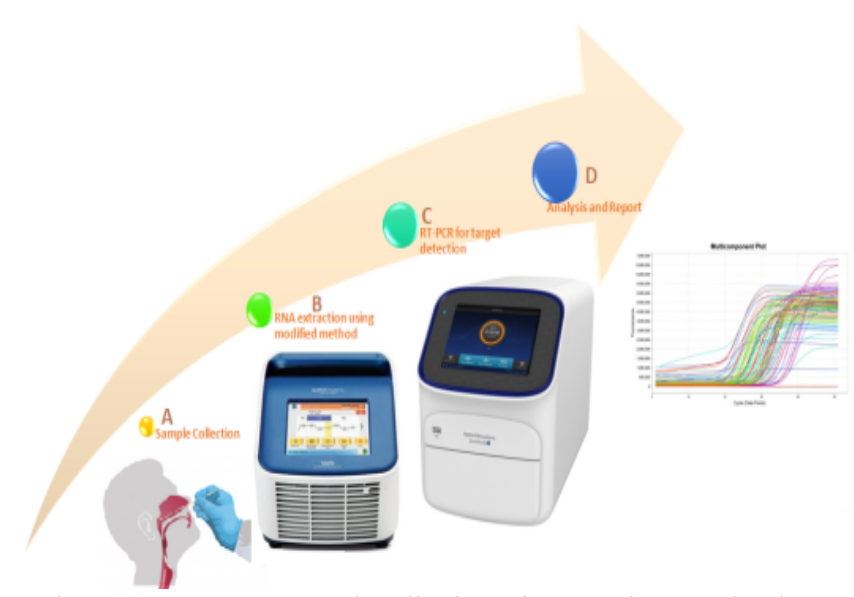

Fig.1. (A) COVID-19 Sample collection using nasopharyngeal and oropharyngeal swab, (B) Heating with proteinase-K and DTT in verity thermal cycler, (C) Real time PCR detection using TaqPath ${ }^{\text {TM }}$ COVID-19 kit on QuantStudio ${ }^{\mathrm{TM}}$ system (D) Analysis of results for target detection. 


\section{RESULtS}

Evidence of an acute SARS-CoV-2 infection depends on the detection of viral RNA species inpatient samples, by targeted amplification and detection of viral genes. The kit used for detection of SARS-CoV-2 infection in clinical samples targets some structural genes and proteins of virus. Positive detection indicates the presence of virus in the given sample. Despite of the limitations of RT-PCR method in analyzing viral load for evaluating disease progression and prognosis, CT value is also important criteria for reporting purpose. Though SARS-CoV-2 detection by RT-PCR is not a quantitative assay but CT values is considered for the therapy purpose and disease progress monitoring. Viral load depends upon the CT values obtained in the RT-PCR results and is inversely proportional to viral load. CT value for captured in present study was ranging from 14 to 37 .

Resulted CT value of each gene was recorded for all the 238 samples. The samples which were negative showed no CT value in any of the genes except MS2 which is used as internal control. In positive samples, sigmoidal curve was observed for each gene (Fig. 1) along with the CT values. CT values of all three genes for each sample extracted using modified method are considered for comparing with reference CT value results of the same sample. For reference $\mathrm{CT}$ values of the samples isolated using standard extraction procedure (King Fisher Flex protocol), average CT value of all three genes was considered for the specific sample. For example, if onesample showed CT value of 21, 22 and 21 for $\mathrm{S}$ gene, $\mathrm{N}$ gene and ORF gene, then 22 will be considered as reference $\mathrm{CT}$ value for that sample. More than one CT difference was not observed in the results in case where standard extraction process was used. In few samples, for all the negative samples tested, results are in $100 \%$ concordance but for positive samples concordance were found to be $91.23 \%$. All discordant results $(8.77 \%)$ are attributed to low positive samples as we found 20 out of 56 samples resulted negative which were actually low positive (Table II).

TABLE II: RT-PCR BASED COVID-19 DETECTION RESULTS USING NEW EXTRACTION PROTOCOL WITH DTT AND PROTEINASE-K

\begin{tabular}{ccccc}
\hline \hline Results & $\begin{array}{c}\text { Samples } \\
\text { Tested }\end{array}$ & $\begin{array}{c}\text { Concordant } \\
\text { Results }\end{array}$ & $\begin{array}{c}\text { Discordant } \\
\text { Results }\end{array}$ & $\begin{array}{c}\text { Concordance } \\
\%\end{array}$ \\
\hline \hline $\begin{array}{c}\text { High } \\
\text { Positive }\end{array}$ & 58 & 58 & 0 & 100 \\
\hline $\begin{array}{c}\text { Moderate } \\
\text { Positive }\end{array}$ & 62 & 62 & 0 & 100 \\
\hline $\begin{array}{c}\text { Low } \\
\text { Positive }\end{array}$ & 56 & 36 & 20 & 64.29 \\
\hline $\begin{array}{c}\text { Negative } \\
\text { Total }\end{array}$ & 52 & 52 & 0 & 100 \\
\hline \hline
\end{tabular}

Amplification curves representing all three genes $\mathrm{S}$ gene, $\mathrm{N}$ gene and ORF gene are presented in Fig.2a, Fig.2b and Fig.2c.
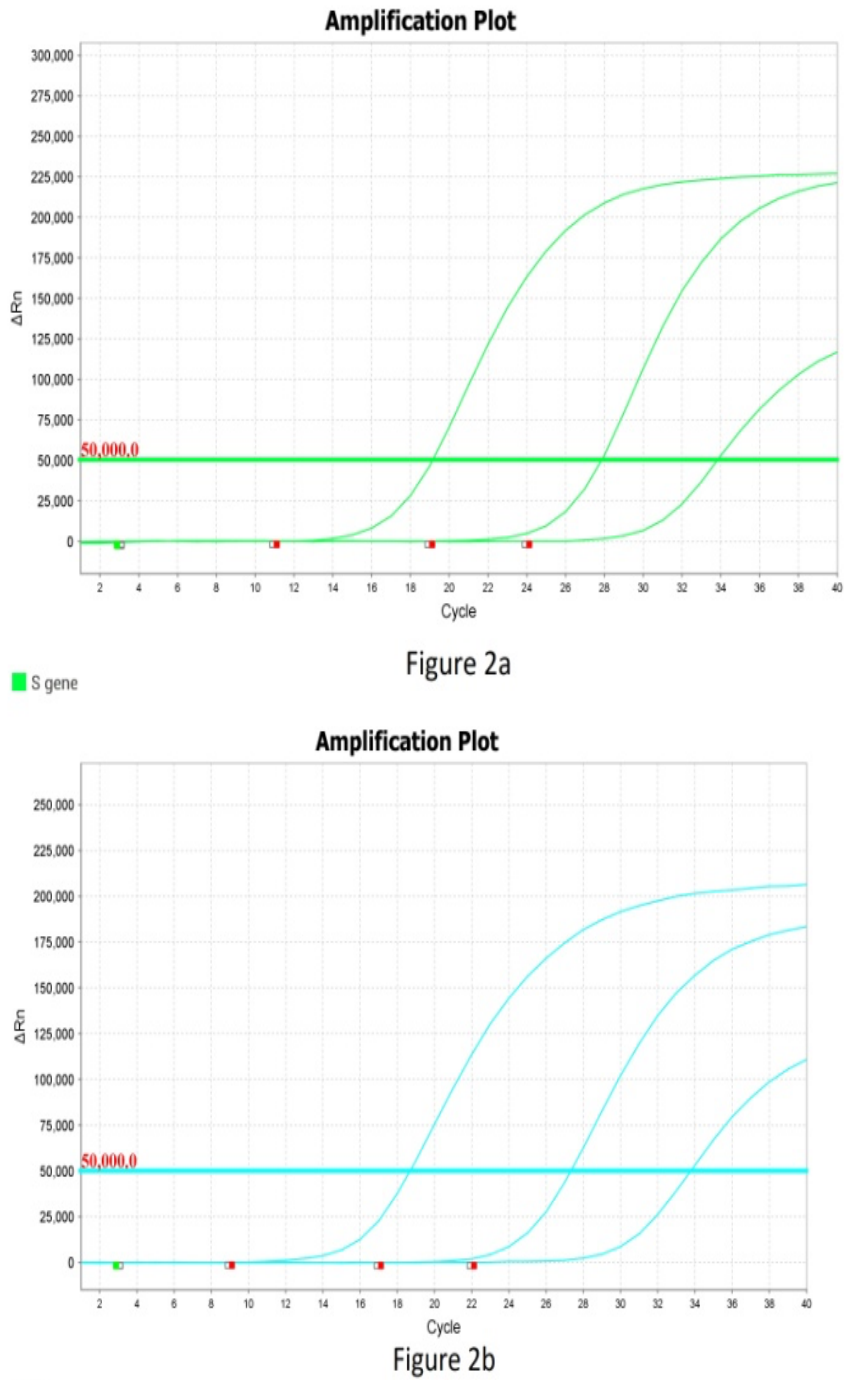

In $\mathrm{N}$ gene

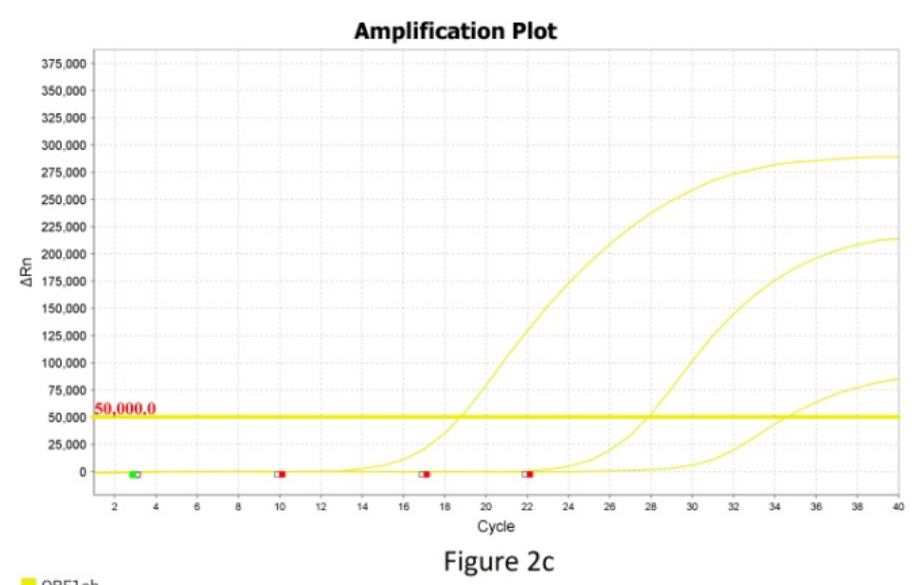

Fig. 2. Amplification curve for three representative samples from whole experiment. 2a: Amplification curve for S gene, 2b: Amplification curve for $\mathrm{N}$ gene, 2c: Amplification curve for ORF gene.

\section{DISCUSSION}

Public health laboratories, hospital laboratories, and commercial laboratories are experiencing exceptional strain in current COVID-19 pandemic as they attempt to keep up with demands for SARS-CoV-2 testing. Despite the availability of many methods like antibody or antigen-based tests, currently, viral nucleic acid detection by reverse transcription-polymerase chain reaction (RT-PCR) is 
regarded as the gold standard for diagnosis of COVID-19 [WHO 2020, National health commission 2020]. As per current recommendations of the Centers for Disease Control and Prevention (CDC) in the United States and the World Health Organization (WHO), traditional reverse transcription-quantitative polymerase chain reaction (RTqPCR) is the best method for COVID-19 detection. The assay requires 2 steps: an RNA extraction from patient nasopharyngeal (NP) swab material, followed by RT-qPCR amplification of the extracted RNA to detect viral RNA [28], [29]. Results are concluded based on the CT values obtained from the assay.

All the samples with CT value from 14 to 37 were considered positive. Clinical disease progression, response to treatment, cure, and relapse etc. can be monitored by quantification of viral load from tissue samples [30], [31]. There are studies available which reported similar viral load in upper respiratory track of diseased patient samples and asymptomatic patients [3], but still viral load monitoring is very important. In our study using newly developed extraction method, we found $11.36 \%$ false negative results in samples with very low viral load i.e. CT values more than 33 .

Of the 228 samples analyzed by new extraction protocol, no false positive results were found. Samples were divided into four categories for analysis purpose which are low, moderate and high positive and negative samples. Criteria for defining low, moderate and high positive and negative sample is already mentioned in the methodology section. Out of 228 samples, 58 samples were found high positive, 62 were moderate positive, 56 were low positive and 52 samples were found negative, results are graphically represented (Fig. 3a). Overall, $91.23 \%$ results were found to be concordant which includes $100 \%$ concordant results for negative samples and $88.64 \%$ concordant results for positive samples (Fig. 3b). Discordant results of positive samples are in case of low positive samples where the reference CT value for more than 33. Reason for these false negative results may be because of RNA quality issues. As the samples used for extraction by the modified protocol were tested first with standard extraction protocol. Of the 56 low positive samples (having CT values from 33 to 37 ) tested with the new extraction method, 36 samples were found to be positive, but CT value was increased by 2 . Rest positive samples including 58 high and 62 moderate positive samples were detected with 1 value higher than reference $\mathrm{CT}$ value.

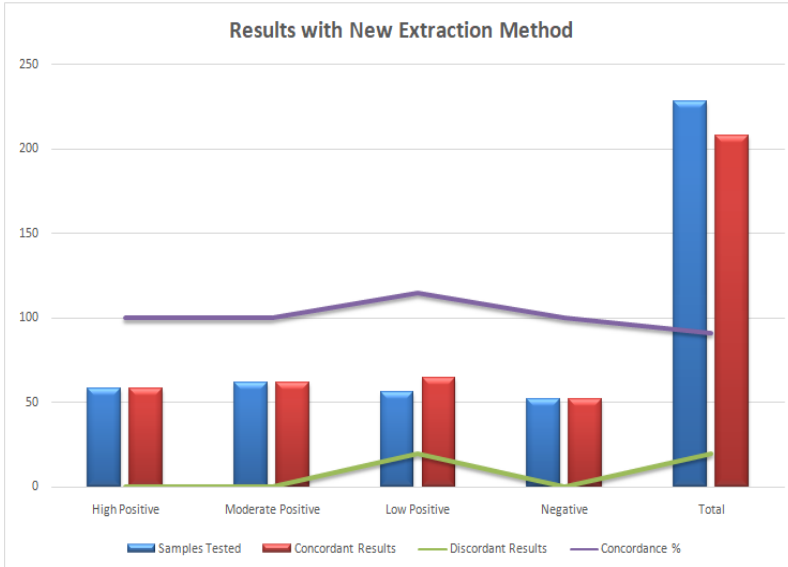

Figure $3 a$

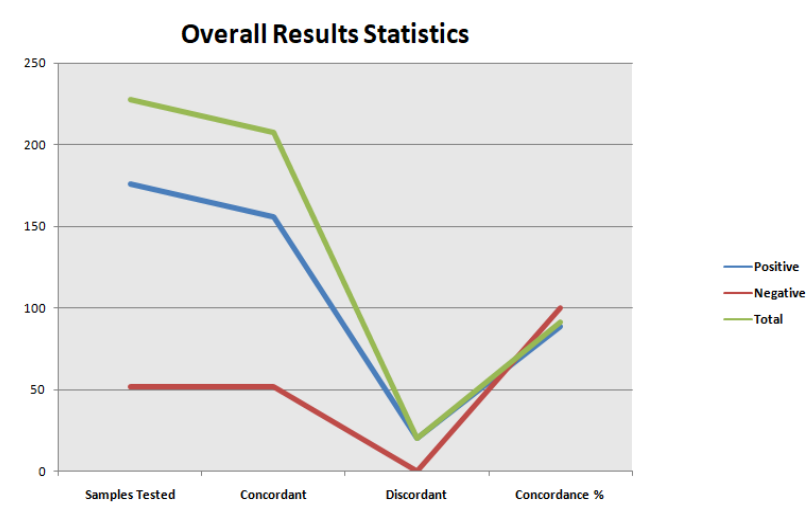

Figure $3 b$

Fig. 3. RT-PCR results using new extraction method. 3a: Comparison of RT-PCR results obtained using new extraction method and existing method among low, moderate and high positive and negative samples. 3b: Overall comparison of RT-PCR results obtained using new extraction method.

In the initial experiments, samples were tested without dilution and $\mathrm{CT}$ value obtained were +3 compared to reference $\mathrm{CT}$ values, which may lead to false negative results in low positive samples. The reason for the false negative results when used without dilution is the presence of inhibitors in the samples. Other studies have also reported impact of diluted samples in reducing the inhibitors and improving CT values [15]. In traditional extraction system, either silica column based, or magnetic bead-based extraction methods are used for viral RNA isolation from VTM tubes [15], which removes impurities from the samples. Only heat treatment might cause coagulation of the proteins, so we used heat inactivation method with DTT and Proteinase-K for isolating RNA from nasopharyngeal or oropharyngeal swab containing VTM. DTT inactivates Ribonucleases (RNases) which degrade RNA during an extraction procedure, stabilizes enzymes and other proteins, which possess free sulfhydryl groups [24]. Other chelating agents like guanidine salts, EDTA and urea also performs similar functions but need to be removed by purification methods as they inhibit PCR reactions [24]. On the contrary, DTT will not interfere with PCR reaction and is widely used in reverse transcription reactions along with other PCR reagents. All the studies conducted globally omitting RNA extraction step, have shown decreased specificity and sensitivity. If any direct method (without extraction) has to be used in clinical context than optimal conditions for use with the direct protocol must be previously tested for each kit [20]. Anika et al., have analyzed 324 samples to study the kinetics of viral RNA detection from the respiratory tract and the relation of RTPCR detection with cultivable virus, which can be used as a proxy for infectiousness to support decisions making on infection control [25]. They concluded that asymptomatic and pre-symptomatic patients can be a source of infectious virus. Furthermore, they added that the significance of low titres of infectious virus for human-to-human transmission remains uncertain because the human infectious dose remains unknown. Patients with CT value $>30$ or $>33$ cannot be ruled out for spreading infection until with observational epidemiological data analyzing known infector-infectee pairs is available to fully understand the dynamics of infectiousness and viral transmissibility. 


\section{CONCLUSION}

To conclude, the present study suggests that COVID-19 RT-PCR test can be performed using proteinase-K and DTT based heat inactivation method instead of extraction kits without affecting the results. This method is easy, cost effective and faster compare to traditional extraction system. Moreover, it decreases manual steps and requirement of extraction systems, kits and reagents which are supply deficit during peak pandemic period. Not having the capability of detecting low positive samples which can be either at the beginning or at end of the disease stage and can be potential carrier of the virus, increases the risk of disease spread in population. But less specificity and sensitivity of such methods raises questions of using the same for diagnostic purpose. However, we believed that such methods can be used for mass screening purpose but not as a clinical diagnostic assay of such an important disease like COVID19.

\section{ACKNOWLEDGMENT}

The authors are grateful to the management of Unipath Speciality Laboratories for providing all the support to conduct the whole experiment.

\section{FUNDING}

No funding was available for this study.

\section{CONFLICT OF INTEREST}

Authors declare that they do not have any conflict of interest.

\section{REFERENCES}

[1] Mutnal MB, Arroliga AC, Walker K, Mohammad A, Brigmon MM, Beaver RM, et al. Early trends for SARS-CoV-2 infection in central and north Texas and impact on other circulating respiratory viruses. $J$ Med Virol. 2020;92(10):2130-8.

[2] Paules CI, Marston HD, Fauci AS. Coronavirusinfections-morethan just thecommoncold. Jama. 2020;323(8):707-8.

[3] Zhou P, Yang X-L, Wang X-G, Hu B, Zhang L, Zhang W, et al. A pneumonia outbreak associated with a new coronavirus of probable bat origin. Nature. 2020;579(7798):270-3.

[4] Chen Y, Liu Q, Guo D. Emerging coronaviruses: genome structure, replication, and pathogenesis. J Med Virol. 2020;92(4):418-23.

[5] Guarner J. Three emerging coronaviruses in two decades: the story of SARS, MERS, and now COVID-19. Oxford University Press US; 2020.

[6] Fehr AR, Perlman S. Coronaviruses: an overview of their replication and pathogenesis. Coronaviruses. 2015;1-23.

[7] Dhama K, Khan S, Tiwari R, Sircar S, Bhat S, Malik YS, et al. Coronavirus Disease 2019-COVID-19. Clin Microbiol Rev.2020;33(4): e00028-20.

[8] Snijder EJ, Decroly E, Ziebuhr J. The nonstructural proteins directing coronavirus RNA synthesis and processing. Adv Virus Res. 2016; 96 : 59-126.

[9] Den Boon JA, Spaan WJM, Snijder EJ. Equine arteritis virus subgenomic RNA transcription: UV inactivation and translation inhibition studies. Virology. 1995;213(2):364-72.

[10] Nedialkova DD, Gorbalenya AE, Snijder EJ. Arterivirus Nsp1 modulates the accumulation of minus-strand templates to control the relative abundance of viral mRNAs. PLoSPathog. 2010;6(2): e1000772.

[11] Zumla A, Al-Tawfiq JA, Enne VI, Kidd M, Drosten C, Breuer J, et al. Rapid point of care diagnostic tests for viral and bacterial respiratory tract infections-needs, advances, and future prospects. Lancet InfectDis. 2014;14(11):1123-35.

[12] Alcoba-Florez J, González-Montelongo R, Íñigo-Campos A, de Artola DG-M, Gil-Campesino H, Team TMTS, et al. Fast SARS-CoV-2 detection by RT-qPCR in preheated nasopharyngeal swab samples. Int J Infect Dis. 2020;97:66-8.

[13] Wee SK, Sivalingam SP, Yap EPH. Rapid direct nucleic acid amplification test without RNA extraction for SARS-CoV-2 using a portable PCR thermocycler. Genes (Basel). 2020;11(6):664.

[14] Bruce EA, Huang M-L, Perchetti GA, Tighe S, Laaguiby P, Hoffman JJ, et al. Direct RT-qPCR detection of SARS-CoV-2 RNA from patient nasopharyngeal swabs without an RNA extraction step. PLoS Biol. 2020;18(10): e3000896.

[15] Smyrlaki I, Ekman M, Lentini A, de Sousa NR, Papanicolaou N, Vondracek M, et al. Massive and rapid COVID-19 testing is feasible by extraction-free SARS-CoV-2 RT-PCR. Nat Commun. 2020;11(1):1-12.

[16] Pearson JD, Trcka D, Lu S, Hyduk SJ, Jen M, Aynaud M-M, et al Comparison of SARS-CoV-2 indirect and direct RT-qPCR detection methods. Virol J. 2021;18(1):1-12.

[17] El-Kafrawy SA, El-Daly MM, Hassan AM, Kaki RM, Abuzenadah AM, Kamal MA, et al. A Direct Method for RT-PCR Detection of SARS-CoV-2 in Clinical Samples. Healthcare. 2021: 37.

[18] Alaifan T, Altamimi A, Obeid D, Alshehri T, Almatrrouk S, Albarrag A. SARS-CoV-2 direct real-time polymerase chain reaction testing in laboratories with shortage challenges. Future Virol. 2021;16(2):133-9.

[19] Castellanos-Gonzalez A, Shelite TR, Lloyd N, Sadiqova A, Ping R, Williams-Bouyer N, et al. Direct RT-PCR amplification of SARSCoV-2 from clinical samples using a concentrated viral lysisamplification buffer prepared with IGEPAL-630. Sci Rep. 2021;11(1):1-10.

[20] Miranda JP, Osorio J, Videla M, Angel G, Camponovo R, HenríquezHenríquez M. Analytical and Clinical Validation for RT-qPCR detection of SARS-CoV-2 without RNA extraction. Front Med. 2020; 7: 673 .

[21] Bruce EA, Tighe S, Hoffman JJ, Laaguiby P, Gerrard DL, Diehl SA, et al. RT-qPCR detection of SARS-CoV-2 RNA from patient nasopharyngeal swab using Qiagen RNeasy kits or directly via omission of an RNA extraction step. BioRxiv. 2020.

[22] Nelson AC, Auch B, Schomaker M, Gohl DM, Grady P, Johnson D, et al. Analytical validation of a COVID-19 qRT-PCR detection assay using a 384-well format and three extraction methods. BioRxiv. 2020.

[23] Lista MJ, Page R, Sertkaya H, Matos PM, Ortiz-Zapater E, Maguire TJA, et al. Resilient SARS-CoV-2 diagnostics workflows including viral heat inactivation. MedRxiv. 2020.

[24] Mommaerts K, Sanchez I, Betsou F, Mathieson W. Replacing $\beta$ mercaptoethanol in RNA extractions. Anal Biochem. 2015; 479: 51-3.

[25] Bullard J, Dust K, Funk D. Predicting infectious SARS-CoV-2 from diagnostic samples. Clin Infect Dis. 2020; 10.

[26] Basile K, McPhie K, Carter I, Alderson S, Rahman H, Donovan L, et al. Cell-based culture of SARS-CoV-2 informs infectivity and safe deisolation assessments during COVID-19. medRxiv. 2020.

[27] La Scola B, Le Bideau M, Andreani J, Hoang VT, Grimaldier C, Colson $\mathrm{P}$, et al. Viral RNA load as determined by cell culture as a management tool for discharge of SARS-CoV-2 patients from infectious disease wards. Eur $J$ Clin Microbiol Infect Dis. 2020;39(6):1059-61.

[28] Chu DKW, Pan Y, Cheng SMS, Hui KPY, Krishnan P, Liu Y, et al. Molecular diagnosis of a novel coronavirus (2019-nCoV) causing an outbreak of pneumonia. Clin Chem. 2020;66(4):549-55.

[29] Corman VM, Landt O, Kaiser M, Molenkamp R, Meijer A, Chu DK. Detection of 2019 novel coronavirus (2019-nCoV) by real-time RTPCR. Euro SurveillFebrauary 2020.

[30] Rainer TH, Lee N, Ip M, Galvani AP, Antonio GE, Wong KT, et al. Features discriminating SARS from other severe viral respiratory tract infections. Eur J Clin Microbiol Infect Dis. 2007;26(2):121-9.

[31] MemishZA, Al-Tawfiq JA, Makhdoom HQ, Assiri A, Alhakeem RF, Albarrak A, et al. Respiratory tract samples, viral load, and genome fraction yield in patients with Middle East respiratory syndrome. $J$ Infect Dis. 2014; 210(10): 1590-4. 


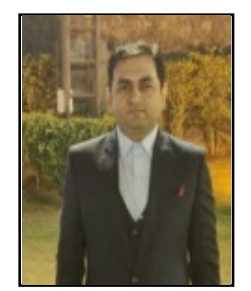

S.Chaudhary is from Gujarat, India. He has completed his Ph.D. in Biotechnology from KSV university, Gandhinagar. In his Ph.D. work, he studied the gene regulation in fenugreek plants. Genes responsible for important secondary metabolites were identified and also carried out up regulation of few genes leading to increase in secondary metabolite production.

Dr. Chaudhary has eleven years of experience in molecular biology and next generation sequencing. He has vast experience in research and medical diagnostics. Being highly skilled in NGS, sanger sequencing and real time PCR techniques, he has developed many tests like EGFR, KRAS, Beta thalassemia detection, denguechikungunya detection etc.

Dr. Chaudhary has published more than 25 research articles and book chapters. He is currently working as a Scientist and Head of Molecular Department at Unipath Specialty Laboratory Limited. In association with Unipath, he is working on developing important diagnostic assays and routine next generation sequencing work. 